\title{
Motivations for Social Networking at Work
}

\author{
Joan DiMicco, David R. Millen, Werner Geyer, \\ Casey Dugan, Beth Brownholtz, Michael Muller \\ IBM Research \\ 1 Rogers Street \\ Cambridge, MA 02142 USA \\ [joan.dimicco; david_r_millen; werner.geyer; cadugan; \\ beth_brownholtz; michael_muller]@us.ibm.com
}

\begin{abstract}
The introduction of a social networking site inside of a large enterprise enables a new method of communication between colleagues, encouraging both personal and professional sharing inside the protected walls of a company intranet. Our analysis of user behavior and interviews presents the case that professionals use internal social networking to build stronger bonds with their weak ties and to reach out to employees they do not know. Their motivations in doing this include connecting on a personal level with coworkers, advancing their career with the company, and campaigning for their projects.
\end{abstract}

\section{Author Keywords}

Social networking, enterprise, user motivation, $\mathrm{CSCW}$

\section{ACM Classification Keywords}

H.5.3 [Information interfaces and presentation]: Group and Organization Interfaces.

\section{INTRODUCTION}

Millions of people are using social network sites to connect, meet, and share [4]. The users of the most popular sites on the Internet, MySpace.com, Facebook.com, Bebo.com, and Orkut.com, are predominantly young-twenties, college students, and teenagers. From prior research we know that these user groups are using the sites to stay in touch with friends $[2,10,20,23]$.

The emergence of specialized social network sites targeted towards specific user groups, such as professionals [29], indicates that social networking can provide value to many types of users, in many different ways. The focus of this research is on understanding how professionals inside of a company use an internal social networking site. Given the popularity of social networking sites on the Internet, it is

Permission to make digital or hard copies of all or part of this work for personal or classroom use is granted without fee provided that copies are not made or distributed for profit or commercial advantage and that copies bear this notice and the full citation on the first page. To copy otherwise, or republish, to post on servers or to redistribute to lists, requires prior specific permission and/or a fee.

CSCW'08, November 8-12, 2008, San Diego, California, USA

Copyright 2008 ACM 978-1-60558-007-4/08/11...\$5.00. expectation that employees will use a company-sponsored tool, it is not known how they will use it or what value they will derive from it.

The research thus far on social network sites (SNSs) has been focused on four main aspects: privacy issues $[1,9,14$, $16,21]$, self presentation $[6,7,13,24]$, network analysis [3, $18]$, and social capital benefits $[10,20]$. As boyd and Ellison summarize: "Although exceptions exist, the available research suggests that most SNSs primarily support pre-existing social relations" [4]. For example, Ellison, et al. found correlations between greater "bridging" and "bonding" social capital with greater usage of Facebook on a college campus [10], meaning that the ties to one's immediate and extended friends are stronger with greater use of Facebook. In conjunction with this work, Lampe, et al. found that Facebook users focus their time on the site looking at the friends they know, rather than browsing through profiles of those they do not know [23]. The goal of our research is to determine how using a social networking site inside of a company differs in terms of social connections and also in terms of different user motivations.

To determine this, we built a social network site behind IBM's firewall called Beehive. As with other social network sites, it supports the "friending" of other people, provides an individual profile page for each user, and incorporates media sharing in the form of photo and list sharing [11]. While we built the site to support sharing between colleagues, we did not build in limitations on the types of content that could be shared, for example whether or not the content was personal or professional in nature.

Shortly after launching Beehive we did usage analysis of several hundred users and found evidence of relationship building and 'people sensemaking' throughout the site [5]. But this analysis left a significant question unanswered: why are people using the Beehive? What are their goals in building relationships and sensemaking? To answer this deeper question, we have focused this analysis on in-depth interviews to understand users' motivations and thoughts on their usage. We followed-up this qualitative analysis with a quantitative overview of the site to determine if patterns observed in interviews were replicated more broadly. 
Through this analysis we have been able to answer these three questions about social networking at work:

\section{Whom do employees connect with?}

Do employees use the site to connect to new or known colleagues? Do they use the site to get to know people or maintain existing close relationships?

\section{What are employees' motivations for using the site?}

While socializing at work may be fun when taking a break, is it what motivates users to return to the site on a regular basis? Or do they find the site supports them in their job?

\section{What type of content is shared on the site?}

As designed, the site does not prescribe whether users should contribute personal or professional content to the site. What will they choose to share about themselves with their colleagues?

The rest of the paper is organized as follows. A discussion of related research puts this research in context with other studies of social software in the enterprise setting. The following section gives a brief overview of the features of Beehive and the current usage statistics. The remaining sections are structured according to our analysis, exploring the three research questions: whom employees connect with, what motivates them to use the site, and what types of content they share.

\section{RELATED RESEARCH}

There is a significant body of existing research on how social software in general is used in a corporate environment. For example, studies have been done on the use of blogging software [19, 22], social bookmarking tools [25] and wikis [17] within the boundaries of an intranet.

This research has found that employees use these tools for search and discovery of new corporate information. Blogs, bookmarks, and wikis represent new repositories of information generated by employees, so while part of using these tools is connecting with fellow employees (hence "social" software), the value of these tools for the average employee is more information-centric than social. Research on the contributors to tagging [28] and blogging [19] systems indicate that contributors to these tools tend to be providing information and striving to be thought leaders and evangelists, rather than seeking information for themselves or connecting in a social manner with colleagues.

Another example of how professionals use social software is the use of Internet sites designed for professionals. The most popular public site for professional networking is LinkedIn.com, with over 20 million registered users. LinkedIn is most commonly used for generating sales leads, finding potential hires, and in general, leveraging the contact lists of fellow colleagues [27]. Again, the focus of users is on information providing and gathering, not on socializing.
From this evidence, we might expect that employees participating in Beehive would focus on being information providers, rather than as social individuals. Particularly because Beehive is hosted by the users' employer, IBM, one might hypothesize that users would be particularly inclined to use the site for work-only purposes.

On the other hand, from what has been observed about Facebook usage by professionals within a single company [6], professionals' Facebook use largely mimics the patterns of use by college students on the site: it is used by professionals to keep in touch with social friends outside of work. So this provides evidence that when using external, general tools, professionals replicate the usage patterns set in place by the other users and participate to socialize.

Because of these inconclusive patterns of use, we anticipated that our users would exhibit some combination of personal and professional behavior on the site. However, before launching the site we did not know how users would balance this and what would be their primary motivations for using the site.

\section{BEEHIVE: A SOCIAL NETWORK SITE FOR EMPLOYEES} At the end of May 2007, we launched Beehive, and one year later the site supported over 30,000 employees. The goal of the site is to enable users to express themselves in rich, personal ways so that other users could get an expressive picture of who an individual was on a personal and professional level.

Seeing the popularity and liveliness of the profiles on Facebook and MySpace, we wanted to bring this level of user participation and community to our company. We observed that this personal and expressive information was generally lacking from our corporate intranet and that our corporate directory had listings for every employee but many of them were void of information. Keeping employee profiles up-to-date with relevant, useful and dynamic information is a significant challenge for many human resources departments.

The overall design of the site is similar to social network sites such as Facebook and MySpace in that the site supports users in creating an articulated social network (referred to as "connections"), sharing content, and creating and customizing profiles.

\section{Beehive Overview}

On Beehive, user profiles are dynamic in that they change depending on a user's activity elsewhere on the site (e.g. creating content or writing comments) and they are customizable in that users can choose which information to display and where it is displayed on the page.

Figure 1 shows a typical profile page. The left side of the profile displays a photo of the profile owner drawn from the centralized IBM corporate directory. Below this is the user's current status message. Status messages on the site are similar to the text messages supported by Twitter.com 
in that they are a dynamic way for a user to notify his/her network of recent activity.

Below the status message is contact information pulled from IBM's corporate directory. This type of linking between intranet services is a unique strength of a tool hosted internally and means that every user is identified by their position and location in the organization.

The center of the profile page shows the content the user has chosen to share with the community. This includes the user's most recently shared photos and lists, the user's connections, and the "about you" section where the user can craft question/answer pairs to provide information about him/herself [8]. The "buzz" section of the profile shows comments left by other users on the owner's profile page, as well as reveals the most recent actions of this individual on the site.

Beyond profiles, Beehive supports the sharing of lists and photos. Lists (Figure 2) provide a way of expressing opinions and sharing interests or information through a structured collection of five ordered items. Examples for lists are "Cities I have lived in," "Last 5 projects I worked on," and "People I just met at a conference" [11]. The site's photo sharing has basic mechanisms for uploading and sharing photos on the site. The layout and structure of a photo page, as shown in Figure 3, is similar to the list page.

As with the profile pages, users can leave comments on individual lists and photos. An example of this is shown at the bottom of the list screenshot in Figure 2. This ability to comment enables the communication and socializing common on external sites.

\section{Privacy Controls}

We designed a simpler access control policy for sharing content than is typical on today's social network sites. To control who sees what content, users can limit the visibility of their photos and lists to their immediate connections or they can choose to allow any site visitor to see their content. In this way, the site supports users who want to use the site to maintain contact with their close colleagues, as well as supports users reaching out to the entire company.

\section{Overview of Site Growth and Patterns}

In the year since launching Beehive (May 2007 - May 2008), the over 30,000 users on the site had contributed over 250,000 friend connections, 27,000 about-you statements, 36,000 status message updates, 32,000 photos, 10,000 lists, and 100,000 comments on content.

The site experienced steady growth over its first year, and based on a data snapshot taken nine months after its launch (the end of February ' 08 ), $67 \%$ of the users were active on the site, with "active" being defined as contributing content or connecting to another user. While $33 \%$ of the users have not contributed content to Beehive, this is not an enormous

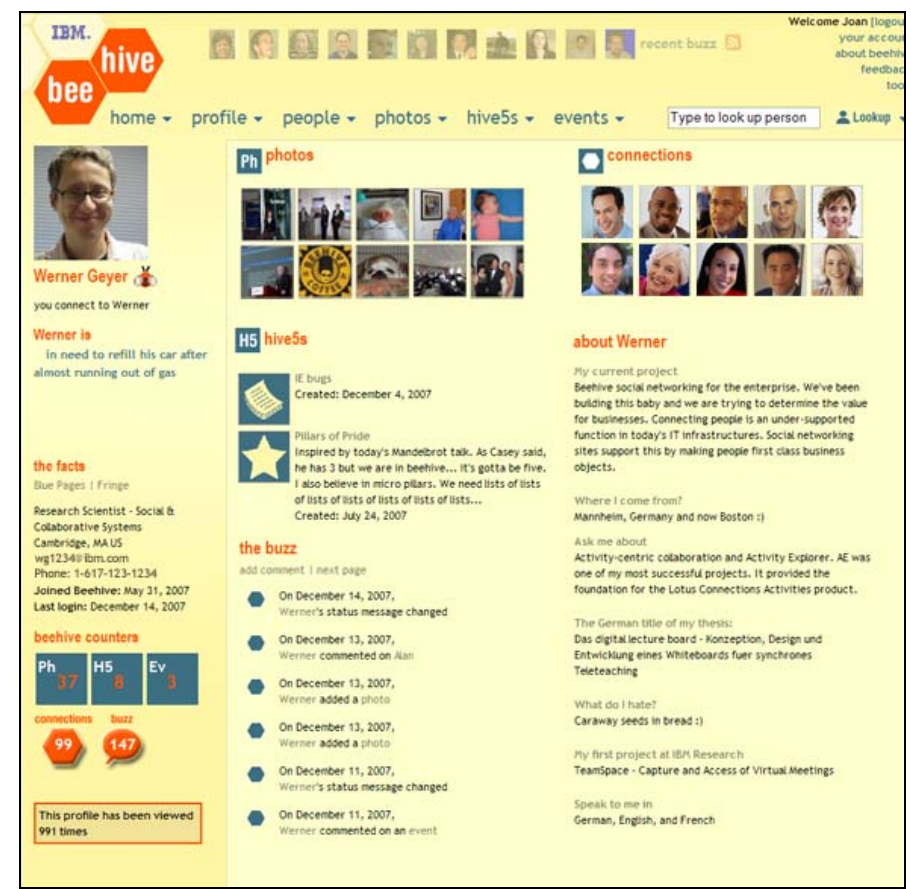

Figure 1. A Beehive profile.

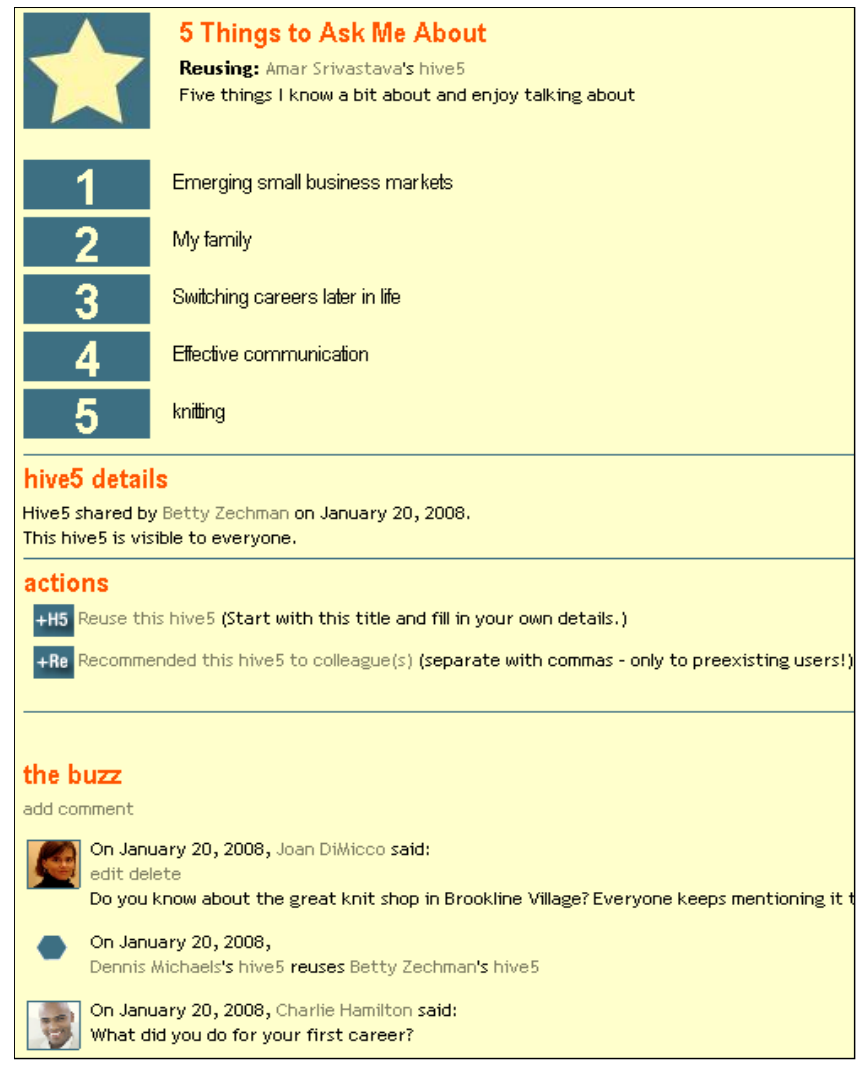

Figure 2. A shared list on Beehive.

surprise, as we expect to have a substantial lurker population as the community matures [26]. Figure 4 breaks down the user contribution levels by the different content types, to show that most users are making connections on the site and a third of the users are setting their status message. 


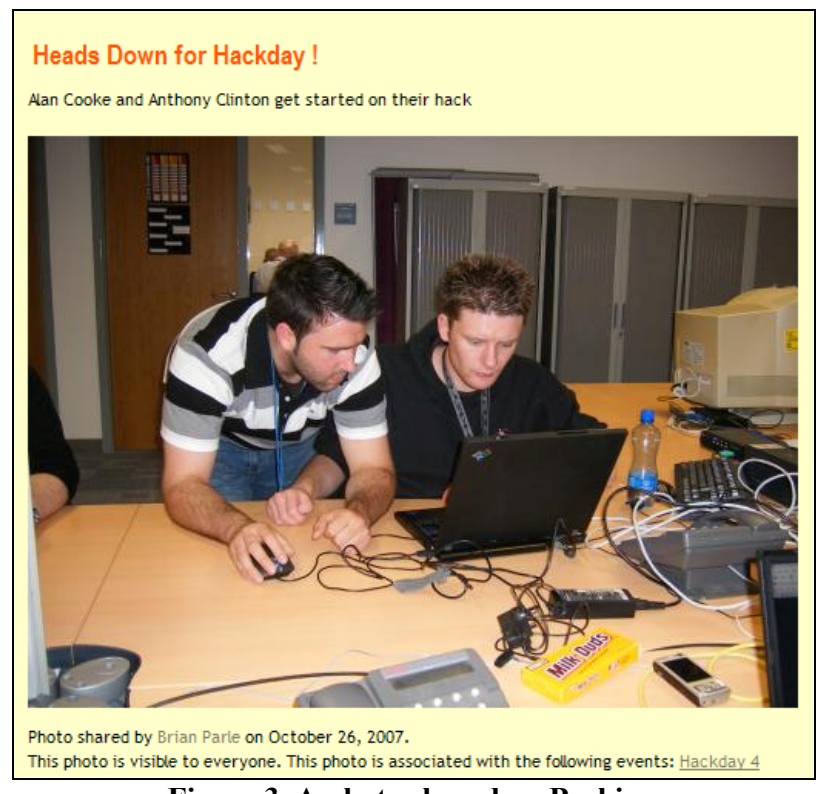

Figure 3. A photo shared on Beehive.

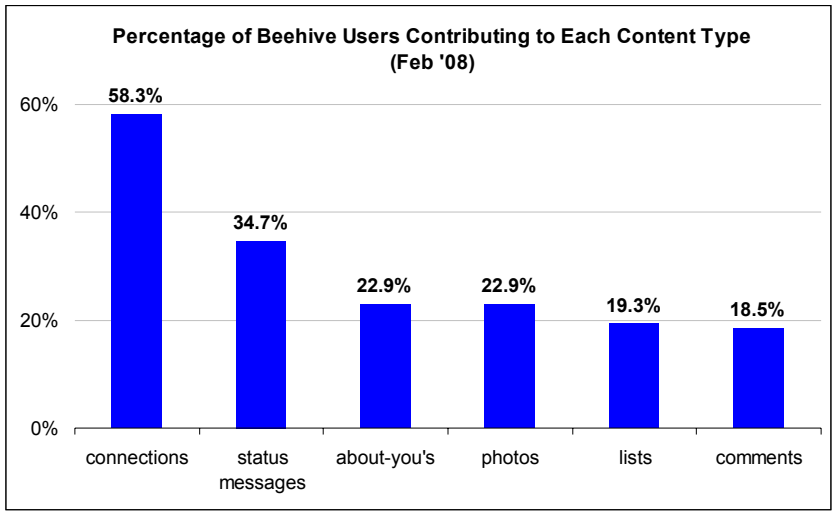

Figure 4. The percentage of users contributing site content.

Based on a broad categorization of job titles, we found that $27 \%$ of the users were engineers or IT workers, $15 \%$ were vice presidents or directors, $10 \%$ were managers or leads, $6 \%$ were consultants and $4 \%$ sales. (The remaining 38\% could not be classified into these general categories.) Fiftyseven countries were represented on the site: $40.6 \%$ of the users were within the US and $14.8 \%$ in India, and these percentages reflect IBM's overall workforce. The remaining 55 countries each had less than $7 \%$ of the user base. Of users specifying an office location in the corporate directory, $31.9 \%$ of them specified "home" or "mobile" as their office, again, reflecting IBM's overall percentage of mobile workers.

The conclusions from these demographics are that Beehive's users are a mix of managerial and technical employees, and their distribution along geographic and mobile measures reflects the overall corporation.

\section{RESEARCH METHODOLOGY}

As described in the introduction, to understand user motivations we conducted qualitative interviews, with supporting quantitative analysis of usage logs. For our analysis we interviewed seventeen users, using a semistructured interview technique. The interviews asked users why they joined Beehive, why they connected to people, and why they shared particular content. We asked them about memorable colleagues and content, about their use of other social software, how they typically communicated with colleagues, and their own perception of the value of the site.

Nine users were interviewed three months after Beehive launched and eight of them were interviewed nine months after the launch. At nine months, we contacted the original subjects to see if their usage or motivations for Beehive had changed. We conducted interviews over the phone, with two of our team members asking questions, taking notes, and recording audio.

We chose these subjects based on their high level of site activity, as well as based on their job function and location, in order to have a mix of non-managers/managers and US/non-US employees. Of the seventeen interview subjects, four were female, seven worked outside of the US, and their job titles ranged from manager to engineer to technical evangelist.

To analyze the interviews, we distilled each audio transcript into distinct statements and coded each into multiple emerging themes. This coding was informed by grounded theory in which the themes were generated through the summarization process [12].

\section{WHO DO EMPLOYEES CONNECT WITH?}

When employees connect with another person on Beehive, they begin receiving updates about that person's activity through the site's home page, email digests, and optional feeds. Therefore, by connecting to someone, you are able to keep detailed track of their activity on the site.

Consistent trends were revealed in our interviews about whom Beehive users connect to and share with on the site. Subjects reported that although they often connected to their immediate colleagues, they did not use the site to share content with them. Instead, they used the site to connect with the "weak ties" [15] in their network: either colleagues they did not know well or ones they had worked with previously but did not communicate with on a regular basis now. With our later set of interviewed users, who were able to interact with thousands more people on the site, there was an increase in stories of users meeting new employees through the site, to make personal and business connections that in some cases have led to significant business and personal interactions outside the site.

\section{Not Sharing With Close Colleagues}

When asked if the site was useful for interacting with immediate colleagues, some users said they started using the site for that purpose, but over time decreased their communication with their close coworkers, as they increased their communication with others on the site: 
"[Keeping up with my team] is typically done via conference calls, emails, Sametime [instant messaging]. I started using Beehive to connect with colleagues, but we are already in daily meetings together. I find myself connecting with people outside my daily colleagues. I already know a lot about them [my daily colleagues].” [Subject 1: Program Manager, male, works from home in Connecticut, USA]

Another user's response to the question 'are you connecting with your closest colleagues' was:

"No, if I can talk to them outside Beehive, we don't need Beehive for that." [S2: Business Requirements Analyst, male, North Carolina, USA]

One of our early interview subjects reported six months after the interview that he had stopped using the site because it was not useful for connecting with his immediate team:

"I have stopped using Beehive. I see the value in Beehive, the problem I have had is getting those that I work with to see the value in Web 2.0 apps like [it]. I would like to start using it again, and possibly try to have some others join in." [S3: Security Specialist, male, Ottawa, Canada]

The exceptions to these explicit statements of not using the site to connect to close colleagues were statements about connecting with formerly close colleagues:

"My closest colleagues, the people I work with everyday, I generally use Sametime [instant messaging] or email more than Beehive. However if they are people I know are active on Beehive, I will send them a note. Like [John Smith], my former manager. We comment on each other all the time. I know he checks his page once a day and is more likely to see that than plow through all his emails." [S4: Manager, female, New York, USA]

From these reports, and from the absence of stories of using the site for keeping up with current colleagues, we believe that users do not use the site to keep up with the colleagues they know well, but rather use it to connect with those they would like to know better, as the next sections will explain.

\section{Getting to Know Weak Ties on a Personal Level}

When we asked subjects if they could recall content on the site that was particularly memorable to them, more often than not the subject recalled the content of someone they knew, but not very well: someone they had met only once and perhaps never face-to-face. The photos and lists of these weak ties within the organization formed lasting impressions on our interviewees and they described learning new things about the people, in particular about their non-work lives. For example, one user described his distant colleague:
"I knew she was a parent, but I don't know her in person besides the one conference I've seen her at. [When I saw her photos, I thought,] 'Oh, that's right, she's a parent. There's the child. There's the husband.' I feel closer to her, as close as if I had had dinner at their house." [S5: Designer, male, North Carolina, USA]

Another user specifically described how he used the site for maintaining his looser connections within the enterprise:

"Beehive helped me ... maintain loose social ties with people I don't have a close, frequent connection with (which is based on a work or friendly relationship), but would like to do some maintenance to my connection with them, for the future's sake." [S6, Software Engineer, male, Haifa, Israel]

As this user so clearly explains, he hopes to strengthen these ties now, so that in the future he can call upon these connections for resources. This classic explanation of the value of weak ties is where some of the value in the site lies, as has been found with Facebook [10].

\section{Meeting New Colleagues}

When we asked our interview subjects how they knew their Beehive connections, many of them said they knew a large proportion of them, up to $75 \%$, exclusively through the site. In several of our later interviews, users said that they now considered some of these online connections to be close colleagues:

"I discovered people in here that are turning out to be very good contacts from a work perspective, just in terms of domain experts and domain interest. Not even involved in stuff I'm immediately working on, just interested in same set of things. " [S2]

One user had a specific strategy for finding people using a friends-of-friends method to discover new, relevant colleagues:

"Browsing contact lists of my contacts ... helped me get better knowledge of who should I know within IBM, by seeing who appears in multiple contact lists. I also learned about informal communities that exist within $I B M$ - the cat lovers, the photographers, and maybe even the people who play strange musical instruments." [S6]

Another user told us about becoming good friends with another user:

"Over time becoming fairly good friends with [Robert Smith]. We share many, many things in common: both getting MBA's, both of Hispanic heritage, etc... cooking, University of Miami, athletic, competitive.

"It is not likely we would have made this connection otherwise. Not likely to have made this - what has become a friendship - without Beehive." [S1] 
His personal friendship with the other user has extended outside of Beehive to email and instant messaging and they hope to meet face-to-face.

Beehive's commenting feature, that allows users to comment on profiles, photos, and lists, was the most commonly mentioned means by which people got to know each other. They would see someone commenting on the same photos and lists as them, and through that interaction would begin to communicate directly and connect to each other. When the relationships extended outside of the site, in addition to email and instant messaging, users also mentioned interacting through blogs and the comments on blogs.

Our observation that employees are meeting on Beehive and forming significant bonds is markedly different from others' findings that people use of Facebook to keep up with their friends and not for "social browsing." [23] We believe this is a unique aspect to social networking within the workplace: employees are open to meeting each other for both personal and professional reasons, perhaps because of existing common ground.

While we can explain why employees are open to meeting new people, it raises the question of why employees want to meet each other. What are their motivations for connecting and sharing?

\section{WHY DO EMPLOYEES SHARE ON THE SITE?}

By summarizing our interview transcripts and considering users' value and benefit statements, three main themes of motivations emerged. Beyond the desire to share on a personal level, which we anticipated would be a primary value for most users, we identified two additional themes of benefits: career advancement and the ability to convince others to support ideas and projects. We have labeled these three motivations as caring, climbing and campaigning. We do not see these motivations as exclusive to one anothersome users may be equally motivated by all three things but we find these categories to be helpful in structuring our understanding of why users actively contribute to the site and connect with colleagues. Of the seventeen interview subjects, 11 expressed caring, 7 expressed climbing, and 4 expressed campaigning. (Three subjects from our first set of interviews did not express strong motivations beyond simply trying it out.)

\section{Caring}

Across all of the interviews there was a constant theme that connecting on a social level was a source of personal satisfaction. The number one reason employees gave for wanting to use the site was that they enjoyed connecting socially at work:

"Beehive, by design, helps me connect to people personally, which helps me to like these people more, which makes me want to work with them." [S7, Designer, female, Maryland, USA]
Another user who works from home reflected that the site supports today's distributed workforce:

"We no longer have the face-to-face contact we had 5+
years ago, so we don't get to 'catch up' on the life side
of work/life, family, what we did on the weekend,
pictures from our holidays, etc. However, we do get to
do that here [on Beehive] so we've added that
interpersonal relationship back in... I'm enjoying being
here and seeing a different side of people I work with."
[S8, Human Resources, female, Maryland, USA]

This desire to connect personally, both to those you may work with and those you don't know, was a tangible and most frequently mentioned benefit to the site.

\section{Climbing}

A set of our users reported that they felt their use of the site was specifically assisting them in their personal career advancement; we label this motivation climbing. Not all users were motivated to use Beehive to climb and in fact four of our interview subjects joked that they thought using the site could harm their jobs. Those that did feel the site could benefit their careers (seven of the subjects) used it in deliberate ways to promote themselves and connect strategically.

For example, Subject 6 interacted with others on the site as a way to become part of a specific community of practice within the company he was interested in.

"In a sense I wanted to get into this community so I entered it by reusing somebody's [list]. And in a friending way, in some social gesture, reused the [list] and get into the community." [S6]

By communicating around topics of professional interest using Beehive's list feature, he was striving to become known as someone knowledgeable on a topic. He said he was using the site "for the future's sake" because the relationships he was forming within this community would help him in his long-term goals.

Another approach taken by those climbing was more akin to traditional social networking done at face-to-face events. By commenting on the profiles of senior managers and getting to know senior employees through the site, some of our subjects were striving to become known to upper management. For example, Subject 4 said:

"Beehive is a way to have people know something about you, maybe remember something about you. In a company with 300,000 people, it is easy to get lost. If you want to advance, people need to know something about you. Obviously you gotta do your job and your manager has to agree you do a good job to advance, but it is all about networking. You never know where your next job will come from, and the more people you can connect with, the bigger set of opportunities for your next job. ” [S4] 
She gave an example of doing this by commenting on two senior employees' profiles about their favorite sports team:

"I connected to both of them on Beehive and joked, 'Gotta make sure Steelers fans stick together.' Both of them wrote back. [In the future] both [will] know if I'm in a meeting with them, 'That's [Sue]. I've met her before. ", [S4]

The subjects who used Beehive for professional networking and climbing were particularly focusing on communicating with more senior employees. From their reports of communicating on the site, the commenting and list features particularly supported their goals.

\section{Campaigning}

The third motivation of campaigning was primarily expressed by users as using Beehive to gather support for their projects. They used the site to solicit support for their ideas and to drive traffic to their project web pages, which they saw as means to move forward with their ideas. Campaigning users also talked about the importance of getting ideas in front of senior management and felt Beehive supported this. For example, Subject 9 feels that the site supports brainstorming company problems:

"You have enough people from corporate wide that you can put an idea out there. It may skip several levels. You don't know which execs might look. It might just be enough to spark interest in someone high enough to get something done. A very good forum [for this] I think." [S9, Data Manager, male, Texas, USA]

Below is an example of how a user was specifically using features of the site to collect feedback on his project from sales people:

"IBM protects sales people from commentary, calls, etc. so what I chose to do, in my status, was actively soliciting feedback on [my project]. Or when somebody from sales joined Beehive, I go after them, asked for their thoughts on [my project]." [S1]

A final user, Subject 10, reported tremendous success at using the site to gather support for her project:

"I was excited, looking and working with Beehive. I was looking for a medium to which I can create a silent army for this transformational work I'm doing outside my job." [S10, Technical Sales, female, works from home in California, USA]

She went on to explain how she built this "silent army:"

"[I've] contacted about 1500 people within Beehive... one-fourth responded with regards to [my project], which was my main goal, and out of that, I now have contacts within IBM that went up to a VP level and I'm actually able to cross connect, ... cross brand, cross divisional. I am able to do it cross divisionally. Otherwise [on IBM's company directory], VPs would look at [me] and dismiss me, and on Beehive they don't." [S10]

These users see Beehive as a unique platform for promoting and campaigning for their projects. The existing corporate communication channels, typically through one's hierarchy, are limiting for these users; the new found freedom to connect and communicate with anyone on the site is providing a new means to achieve users' project goals.

\section{WHAT DO EMPLOYEES SHARE?}

Now that we have presented that users are connecting to weak and new ties and are motivated by desires to care, climb and campaign, it is worthwhile to examine the shared content on the site through this lens. As shown previously in Figure 4, the most popular activity on the site has been connecting to colleagues and the next most popular activity has been setting status messages. Figure 5 shows that, of the users who do each of the site's activities, the most frequent action is writing comments (20.3 per user), then adding connections (11.2 per user), which are followed by photos, status messages, about-you's and list sharing. By looking at the content in more detail, through our interviews and an analysis of a sampling, we have indications of employees' motivations for sharing within the different content types.

\section{Open Sharing}

During our interviews we asked users how they thought about sharing content inside the intranet versus outside (if they were users of an external social network site). While two of our interviewees stated that they censored their contributions inside to keep them tailored for a business audience, more interviewees expressed that they were willing to share more information inside the company, because they were less concerned about ramifications of both sharing personally identifying information and opinions about IBM. For example:

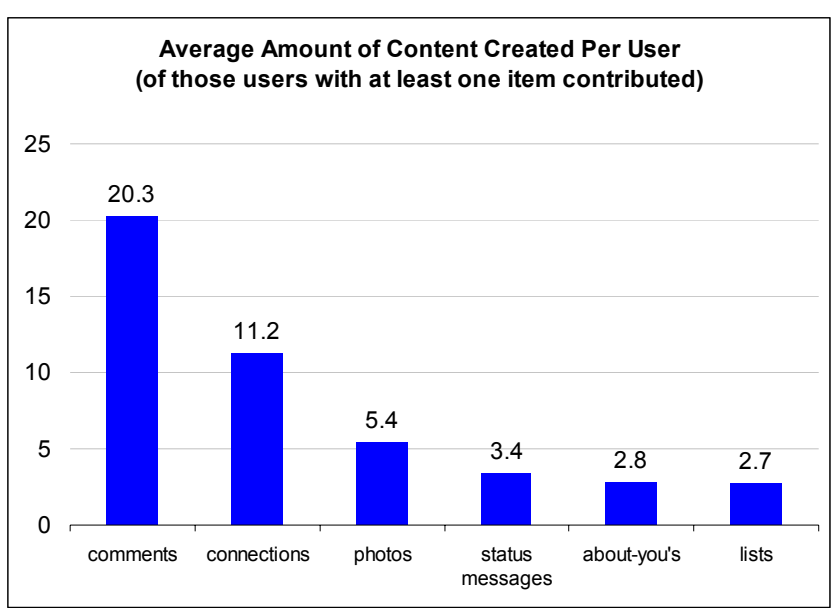

Figure 5. Average amount of content per user. (Feb '08) 
Table 1. Examples of site content, categorized by users' goals of caring, climbing, or campaigning

\begin{tabular}{|c|c|c|c|}
\hline & Caring & Climbing & Campaigning \\
\hline Lists & $\begin{array}{l}\text { Hobbies, outside interests: } \\
\text { - Cities I've lived in } \\
\text { - } 5 \text { Instruments I've played } \\
\text { - Favorite American Idol } \\
\quad \text { Contestants }\end{array}$ & $\begin{array}{l}\text { Skills, background: } \\
\text { - My Practice Areas } \\
\text { - } 5 \text { IBM Sites I've Worked At } \\
\text { - } 5 \text { Big Lessons Learned at IBM } \\
\text { - My Team (and extended team) }\end{array}$ & $\begin{array}{l}\text { Thoughts on professional topics and advice: } \\
\text { - Must See Presentations at [Conference] } \\
\text { - What list topics could buzz up a new angle on local } \\
\text { growth markets? } \\
\text { - Seeking top } 5 \text { IT technical skills in demand in AU }\end{array}$ \\
\hline Photos & $\begin{array}{l}\text { Personal: } \\
\text { - Family holiday picture } \\
\text { - Vacation pictures } \\
\text { - The team socializing }\end{array}$ & $\begin{array}{l}\text { Work-related photos: } \\
\text { - Headshot } \\
\text { - Important conference } \\
\text { - Meetings with key people }\end{array}$ & $\begin{array}{l}\text { Variety of photos: } \\
\text { - Related to project or campaign }\end{array}$ \\
\hline $\begin{array}{l}\text { About- } \\
\text { you's }\end{array}$ & $\begin{array}{l}\text { Hobbies, outside interests: } \\
\text { - What do I do when I'm not } \\
\text { at work? } \\
\text { - Do you call it "pop," "soda," } \\
\text { or "coke?" } \\
\text { - Where did you grow up? }\end{array}$ & $\begin{array}{l}\text { Projecting experience, resume: } \\
\text { - My past projects } \\
\text { - Education } \\
\text { - What are you most passionate about? } \\
\text { - What are your career goals? }\end{array}$ & $\begin{array}{l}\text { Project description, goals, links to other: } \\
\text { - Kelly's and my [innovation] idea! } \\
\text { - Try the new Web2.0 Intranet Search Engine } \\
\text { - What am I up to at the moment? }\end{array}$ \\
\hline Status & $\begin{array}{l}\text { Activities, state of mind: } \\
\text { - Is getting another coffee... } \\
\text { - Is glad he can play paddle } \\
\text { tennis again } \\
\text { - On vacation in Tampa } \\
\quad \text { Florida! }\end{array}$ & $\begin{array}{l}\text { Emphasis on current work: } \\
\text { - Is challenged by time management } \\
\text { - Is in Minneapolis. Back Tue July } 17^{\text {th }} \\
\text { - Is desperately trying to wring } \\
\text { everything possible out of his last } \\
\text { days on assignment in the CIO's office }\end{array}$ & $\begin{array}{l}\text { Goal and opinion oriented: } \\
\text { - Is searching for A/NZ based people interested in Web } \\
2.0 \text { tools, knowledge networking, collaboration! } \\
\text { - Is busy promoting the E\&E video contest }(2 / 25-4 / 11) \text {. } \\
\text { Talk it up! }\end{array}$ \\
\hline
\end{tabular}

"Well, inside, I share what I think IBM is doing wrong... I would not do that in a public environment. I would share more stuff inside than outside. Outside there are things people do not need to know." [S11, Knowledge Manager, male, Spain]

Interviewees frequently said they did not share personal details, such where they lived, on a public site because of privacy concerns, yet they have shared these details on Beehive:

"I willingly make comments about myself I would never make on Facebook. On Facebook I say I live in Houston, Texas. I live in Kingston, 20 miles north. In Beehive I say Kingston. I would prefer they [Facebook users] not narrow me down." [S12, Database Engineer, male, Texas, USA]

This willingness to have other employees hear your honest opinions and know personally identifying information may indicate a high level of trust of other employees. Another indication of a willingness to share openly on Beehive is the low use of the site's privacy controls. When sharing content on the site, users can choose to share their content with just their direct network of connections or with everyone on the site, which as the site grows, is a growing proportion of the company. Of the thousands of shared lists and photos, only $7 \%$ of photos and $3 \%$ of lists have been restricted to visibility by the direct connections only. This openness is a marked difference from users on Facebook, where between 20\% [21] and 40\% [14] of users have limited their profiles' visibility through Facebook's privacy settings. It also relates to our earlier analysis. In order to meet new colleagues and to successfully career climb or campaign, one's profile content needs to be visible to an audience larger than one's direct connections.

\section{Content Themes}

A useful way of understanding what people are sharing is to see examples of site content from the perspective of our three themes: caring, climbing, and campaigning. Table 1 shows specific, representative examples of content we selected from the site for each content type (lists, photos, about-you's, and status messages), broken down into these three types. Caring users share hobbies and outside interests through lists and about-you's, share their personal life through photos, and express their state of mind and outside activities through status messages. Climbing users focus on their skills and background in their lists and about-you's, use photos to reflect their project work, and use status messages to emphasize their current work responsibilities. Campaigning users write lists to express their thoughts on different professional topics, describe their projects in their about-you's, do not have a strong use of single type of photo, and use status messages to indicate a goal or a desire for others to contact them.

To understand how broadly our three themes are represented on Beehive, we took a random sample of 100 users (none of which were our interview subjects) and categorized each of their lists, photos, about-you's, and status messages as either messages of caring, climbing, or campaigning. The results are summarized in Figure 6. This sampling provides an indication that approximately half of lists, about-you's, and status messages are connecting on a personal level, and almost all photos are. About-you's support the self-presentation goals of climbers the most, and lists and status messages have the highest amounts of content supporting campaigning.

This small sampling across the site suggests that the different content types support different types of goals and users may be drawn towards using one type over 
another given their motivation. We plan to do a more thorough analysis of the site's content from this perspective of user motivations, in order to evaluate this conjecture.

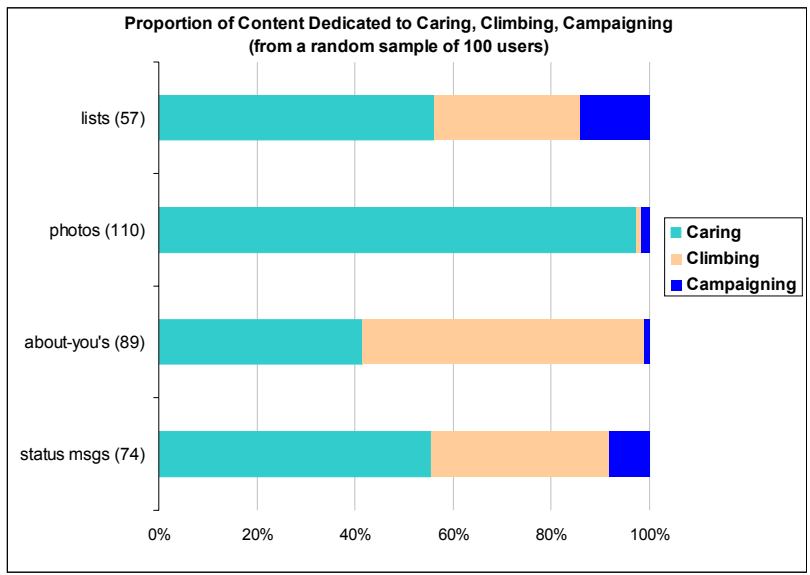

Figure 6. Categorization of content from 100 random users

\section{IMPLICATIONS}

In deploying Beehive, we found that employees are willing and interested in joining an intranet social network site for sharing both personal and professional information with their colleagues [5]. But beyond that, this analysis of their motivations and use of the site has several general implications for social software within a company setting.

\section{Weak and New Ties vs. Strong Ties}

Unlike related research on Facebook and other Internet social network sites, we found that our users are not using the site for keeping up with close colleagues. Rather than "social searching" as Lampe, et al. defined it [23], employees are using the site for "social browsing:" discovering and connecting with colleagues that they do not know at all. Employees use the site to reach out across team and division boundaries to connect with people around similar interests.

While Beehive supports keeping up with close colleagues, such as providing network notifications and privacy options, our findings indicate that connecting beyond one's own network is one of the key activities and motivations for using Beehive. Therefore we recommend enterprise social software specifically support users in discovering new colleagues and finding distant ones through serendipitous exploration and searching around common interests.

\section{Supporting Careers and Campaigns}

Based on our interviews and the follow-up content analysis of the site, it appears that employees are motivated to use Beehive for three reasons: connecting on a personal level, advancing their career within the company, and campaigning projects and ideas within the company. While we expected to find that personal sharing was a perceived benefit, we were surprised to discover users with explicit goals around career advancement and promotion of projects. Connecting to others through commenting was reported by our interview subjects as a critical feature to achieve these goals and there is indication that different content types are more conducive to these activities; the profile about-you's support climbing and lists and status messages support campaigning. Social software within a company can play a valuable role in the promoting of employees and their projects. While further study of these motivations and how they relate to social software use is needed, we recommend that social networking sites allow for public commenting and multiple, flexible means for users to express themselves and their career goals.

\section{Privacy Less of a Concern within the Enterprise}

While privacy concerns are on the rise for the social networking sites on the Internet, we found an absence of concerns within the enterprise. Because of this, we see no indication yet of a need for extensive privacy controls for intranet social software. Furthermore, open sharing across the enterprise specifically enables connecting with new colleagues, climbing, and campaigning.

\section{The Benefit for Companies}

From an enterprise perspective, it is becoming increasingly important for companies to provide internal social software tools. Given that the next generation of employees uses social software as their dominant communication means, companies need to bridge generational gaps and boundaries by supporting this method of communication between employees. Yet, the benefits go beyond generational change. First, a high percentage of users are managers and senior level employees, indicating that Beehive has appeal to a wide variety of users. Second, by bringing this social tool inside the enterprise, the associated data relating to the connections, interests and activities of employees are suddenly available and archive-able by the company, providing new information sources and new possibilities for understanding the workforce. If these tools are not provided by the company, employees may seek social communication tools outside of the enterprise, such as using Facebook, and as a result moving critical communication and information outside the firewall.

\section{CONCLUSION}

Our study of a social network site inside the enterprise reveals that patterns of use and user motivations differ from users of Internet social network sites. Within the walled garden of the enterprise, employees choose to reach out and meet new people rather than only connecting to those they know. They also share details of their life outside of work which has not been found with 
any frequency in other enterprise social software tools. If motivated by career advancement goals or a desire to champion a project idea, they use the social network site strategically to connect and spread their message to a large audience.

\section{REFERENCES}

1. Acquisti, A. and Gross, R. Imagined Communities: Awareness, Information Sharing, and Privacy on the Facebook. Privacy Enhancing Technologies (2006), 36-58.

2. Boyd, d. Identity Production in a Networked Culture: Why Youth Heart MySpace Presented at the American Association for the Advancement of Science, St. Louis, MO, 2006.

3. Boyd, d.m., Friendster and publicly articulated social networking. In Proc CHI '04, Extended Abstracts (2004), 1279-1282.

4. Boyd, d.m. and Ellison, N.B. Social network sites: Definition, history, and scholarship. Journal of CMC, 13, 1 (2007).

5. DiMicco, J.M., Geyer, W., Dugan, C., Brownholtz, B. and Millen, D.R., People Sensemaking and Relationship Building on an Enterprise Social Networking Site. In Proc HICSS '09 (to appear) (2009).

6. DiMicco, J.M. and Millen, D.R., Identity Management: Multiple Presentations of Self in Facebook. In Proc ACM Group Conference (2007).

7. Donath, J. and boyd, d. Public displays of connection. BT Technology Journal, 22, 4 (2004), 71-82.

8. Dugan, C., Geyer, W., Muller, M., DiMicco, J.M., Brownholtz, B. and Millen, D.R., It's All 'About You' - Diversity in Online Profiles. In Proc CSCW '08 (2008).

9. Dwyer, C., Hiltz, S.R. and Passerini, K., Trust and Privacy Concern Within Social Networking Sites: A Comparison of Facebook and MySpace. In Proc AMCIS 2007 (2007).

10. Ellison, N.B., Steinfield, C. and Lampe, C. The Benefits of Facebook "Friends:" Social Capital and College Students' Use of Online Social Network Sites. Journal of CMC, 12, 4 (2007), 1143-1168.

11. Geyer, W., Dugan, C., DiMicco, J.M., Millen, D.R., Brownholtz, B. and Muller, M., Use and Reuse of Shared Lists as a Social Content Type. In Proc CHI '08 (2008).

12. Glaser, S. and Strauss, A. Discovery of Grounded Theory: Strategies for Qualitative Research. Aldine, New York, 1967.

13. Gosling, S., Gaddis, S. and Vazire, S., Personality Impressions Based on Facebook Profiles. In Proc International Conference on Weblogs and Social Media (2007).

14. Govani, T. and Pashley, H. Student Awareness of the Privacy Implications When Using Facebook. Privacy
Policy, Law, and Technology Course, Carnegie Mellon University, 2005, http://lorrie.cranor.org/ courses/ fa05/ tubzhlp.pdf.

15. Granovetter, M.S. The Strength of Weak Ties. The American Journal of Sociology, 78, 6 (1973), 13601380.

16. Gross, R. and Acquisti, A., Information Revelation and Privacy in Online Social Networks (The Facebook case). In Proc ACM Workshop on Privacy in the Electronic Society (WPES '05) (2005).

17. Hasan, H. and Pfaff, C.C., The Wiki: an environment to revolutionise employees' interaction with corporate knowledge. In Proc OZCHI '06 (2006), 377-380.

18. Heer, J. and boyd, d., Vizster: Visualizing Online Social Networks. In Proc InfoVis 2005 IEEE Symposium on Information Visualization (2005).

19. Jackson, A., Yates, J. and Orlikowski, W., Corporate Blogging: Building community through persistent digital talk. In Proc HICSS'07 (2007), 80.

20. Joinson, A.N., Looking at, Looking up or Keeping up with People?: Motives and Uses of Facebook. In Proc CHI '08 (2008), 1027-1036.

21. Jones, H. and Soltren, J.H. Facebook: Threats to Privacy. Ethics and the Law on the Electronic Frontier Course, Massachusetts Institute of Technology, 2005, http://ocw.mit.edu/ NR/ rdonlyres/ Electrical-Engineering-and-ComputerScience/ 6-805Fall-2005/ 8EE6D1CB-A269-434EBEF9-D5C4B4C67895/ 0/ facebook.pdf.

22. Kim, S.T., Lee, C.K. and Hwang, T. Investigating the influence of employee blogging on IT workers' organisational citizenship behaviour. International Journal of Information Technology and Management, 7, 2 (2008), 178-189.

23. Lampe, C., Ellison, N. and Steinfield, C., A face(book) in the crowd: social searching vs. social browsing. In Proc CSCW 2006 (2006), 167-170.

24. Lampe, C., Ellison, N. and Steinfield, C., A Familiar Face(book): Profile Elements as Signals in an Online Social Network. In Proc CHI '07 (2007).

25. Millen, D.R., Feinberg, J. and Kerr, B., Dogear: Social bookmarking in the enterprise. In Proc $\mathrm{CHI}$ '06 (2006), 111-120.

26. Millen, D.R. and Patterson, J.F., Stimulating social engagement in a community network. In Proc CSCW 2002 (2002), 306-313.

27. Salz, P.A. Social networking tools on the road to enlightenment. EContent, October issue (2006).

28. Thom-Santelli, J., Muller, M.J. and Millen, D.R., Social Tagging Roles: Publishers, Evangelists, Leaders. In Proc CHI '08 (2008), 1041-1044.

29. Vascellaro, J.E. Social Networking Goes Professional: Doctors, Salesmen, Executives Turn to New Sites to Consult, Commiserate With Peers; Weeding Out Impostors. in Wall Street Journal, Washington, D.C., August 28, 2007. 